\title{
Impactos positivos da liderança no processo produtivo
}

\author{
Positive impacts of leadership in manufacturing process \\ Willian Toneli da Silva 1; Eduardo Otávio de Mesquita 2; Suzana Kelly Carvalho Ferreira 3 \\ RESUMO
}

O aumento da competitividade vem promovendo importantes mudanças nas estruturas organizacionais, fazendo com que o nível de produtividade aumente

1 E-mail: wtoneli@yahoo.com.br; Faculdades Unidas do Norte de Minas (Funorte,

\section{E-mail:}

eduardootaviomesquita@yahoo.co m.br Faculdades Unidas do Norte de Minas (Funorte,)

3 E-mail: suzanakellyc@gmail.com; Faculdades Unidas do Norte de Minas (Funorte, cada vez mais. Neste contexto organizacional constata-se que a presença do líder exerce um importante papel nesse processo de mudança, uma vez que a organização depende totalmente da produtividade para sua sobrevivência. Com isso, as competências interpessoais são apontadas como fator determinante para o sucesso, e os indivíduos que conseguem se adaptar, redefinindo prioridades e promovendo crescimento e desenvolvimento organizacional sustentável, são percebidos como líderes. O objetivo deste trabalho é analisar os impactos positivos que a liderança gera sobre o liderado e sua contribuição para a produtividade, através da pesquisa, Os Impactos Positivos da Liderança no Processo Produtivo de duas empresas utilizamos como metodologia a pesquisa explicativa, exploratória, bibliográfica, levantamento técnico, aplicação de questionário e pesquisa quantitativa. Os dados coletados foram analisados e apresentados nos resultados da pesquisa. Realizou-se a discussão dos resultados tomando como base pesquisas de outros autores. Dentre os resultados, destaca-se que na empresa Alfa o líder atual não é bem avaliado pelos funcionários, principalmente pela falta de comunicação entre líder e liderados, sendo que o faturamento da empresa em sua gestão é inferior ao faturamento da empresa na gestão do líder anterior sendo respetivamente o faturamento de 52\% (líder atual) e 78\% (líder anterior). Na empresa Beta, porém, o líder atual tem boa aceitação e foi bem avaliado pelos funcionários, sendo o faturamento atual da empresa de $76 \%$ e o anterior de $78 \%$. Percebeu-se através desta pesquisa que uma liderança eficaz é capaz de contribuir para o aumento da produtividade da empresa e impactar positivamente nos seus resultados.

PALAVRAS-CHAVE: Competitividade; Liderança; Produtividade.

\section{ABSTRACT}

Increased competitiveness has promoted important changes in organizational structures, causing the level of productivity increase more and more. In the organizational context it is noted that the presence of the leader plays an important role in this process of change, since the organization depends entirely on productivity for their survival. With this, interpersonal skills are cited as key factor for success, and individuals who can adapt, redefining priorities and promoting sustainable growth and organizational development are perceived as leaders. The objective of this paper is to analyze the positive impact that leadership has on the led and its contribution to productivity through research, The Positive Impact of Leadership in Manufacturing Process two companies used as the methodology explanatory, exploratory, literature, survey research technician, using a questionnaire and quantitative research. The collected data were analyzed and presented in the search results. Was held to discuss the results, based on the research of other authors. Among the results, it is emphasized that the company Alfa current leader is not well evaluated by staff, particularly the lack of communication between leader and led, and the turnover of the company during his tenure is less than the revenue of the company in the management of the leader before being respectively $52 \%$ of the revenue (current leader) and 78\% (former leader). In Beta now, however, the current leader is well accepted and has been favorably reviewed by staff, and the current company revenues of $76 \%$ and above $78 \%$. Was realized through this research that effective leadership is able to contribute to the increase company productivity and positively impact your results.

KEYWORDS: Competitiveness; Leadership; Productivity. 


\section{Introdução}

A liderança nas organizações desempenha papel fundamental nas mesmas, pois o líder é o responsável pela motivação da sua equipe e uma equipe motivada tem subsídio maior para desempenhar as funções a que são atribuídas; e, dessa forma, alcançar as metas impostas pela organização.

Para Antunes e Harvey, apud Silva e Cunha (2014) tempos atrás, as pessoas desempenhavam funções relativamente estáveis nas organizações. No início do século XX, a prática da administração, focava a cumprimento das atividades rotineiras dos operários. Nesse modelo organizacional com características dos padrões de Taylor e Ford, o trabalhador devia obediência ao gestor, desenvolvendo exclusivamente as habilidades indispensáveis à realização de sua tarefa, em única função específica. Assim, havia uma estabilidade considerável nos cargos.

Tendo em vista, a competitividade, Stéfano et alli. (2014) assegura que o mercado de trabalho, por sua vez, se encontra em significativa dificuldade para as organizações, quer seja na contratação ou na conservação de pessoas dentro da organização.

Conforme relatos de Pereira e Schmidt (2008) a ampliação do mercado internacional e as mudanças constantes no ambiente externo tornam mais flexíveis as empresas e seus processos. As novas demandas do mercado modificam os conceitos do sistema mecanicista, transformando-o em um sistema de inter-relações, nas organizações. A empresa dos dias atuais necessita quebrar seus paradigmas e aparelhar seus colaboradores para esse processo de mudança constante. Somente assim, ela será capaz de obter bons resultados e atender a seus clientes com eficácia e rapidez.

O aumento da competitividade vem promovendo importantes mudanças nas estruturas organizacionais, fazendo com que o nível de produtividade aumente cada vez mais. No âmbito organizacional constata-se que a presença do líder exerce um importante papel nesse processo de mudança, uma vez que a organização depende totalmente da produtividade para sua sobrevivência. Em um mercado competitivo com grandes exigências na busca da qualidade total as organizações vêm aumentando suas exigências em relação aos seus colaboradores, que para conseguir atender a demanda das empresas tendem a aliar suas competências técnicas e interpessoais.

Segundo Pereira e Shimidt (2008) O conceito de liderança é um dos mais importantes no processo de mudança dentro das organizações. O sucesso de um empreendimento depende do papel de cada pessoa e de como ela é conduzida por seus lideres.

Conforme Arruda, Crisóstomo e Rios (2012, p.2)

O tema liderança é recorrente, importante e desafiador, englobando variáveis como tipos de poder e autoridade, características pessoais de líderes e liderados, 
inter-relações sociais, poderes atribuídos aos cargos, necessidade de alcançar objetivos corporativos e conjuntos de competências desejadas e necessárias ao seu exercício. A preocupação com esse tema existe desde o começo da humanidade, com muitos historiadores enunciando que o desenrolar da história humana esteve, e ainda está, sujeito à ação de líderes privilegiados e únicos e que a história dos povos é a somatória das biografias destas pessoas.

Diante disso as organizações enfrentam um grande problema falta de lideranças qualificadas. O que faz necessário, por parte das empresas, desenvolver líderes um grande desafio, mas que gera resultados positivos caso obtenham sucesso. Não obstante, o déficit de talento de liderança disponível é citado como um dos limitadores do crescimento empresarial, dada a importância de lideranças eficazes. A empresa que conseguir fazer o desenvolvimento de lideranças eficazmente obterá grande vantagem competitiva no mercado em que atua (VIEIRA, 2011).

No contexto organizacional o líder fornece os meios para a maior parte dessa simplificação. O líder oferece um ponto focal logicamente convincente e emocionalmente gratificante para as pessoas que estão tentando entender as causas e as consequências das tarefas organizadas. Concentrar-se no líder reduz as complexidades organizacionais às condições simples que as pessoas conseguem entender e comunicar. Dessa forma, a liderança está mais relacionada a lidar com desafios, e o gerenciamento pode ser relacionado a lidar com a complexidade organizacional (STÉFANO, 2008).

\subsection{Contextualizando a liderança nas organizações}

A liderança é um tema importante para os gestores devido ao papel fundamental que os líderes representam na eficácia do grupo e da organização. Os líderes são responsáveis pelo sucesso ou fracasso da organização, pois deles dependem o bem estar organizacional, bem como a motivação do grupo (ROSA, 2011).

Dentre as diversas definições para liderança, talvez a mais sucinta seja a de Stoner e Freeman (2009, p. 344) onde definem liderança como: "O processo de dirigir e influenciar as atividades relacionadas às tarefas dos membros de um grupo".

De acordo com Williams (2010, p. 286 apud REIS et al,2012) liderança é o processo de influenciar outras pessoas para atingirem um conjunto de objetivos organizacionais.

Neste diapasão, para Chiavenato (2006, p.18-19)

\footnotetext{
A liderança é necessária em todos os tipos de organização humana, seja nas empresas, seja em cada um de seus departamentos. Ela é essencial em todas as funções da Administração: o administrador precisa conhecer a natureza humana e saber conduzir as pessoas, isto é, liderar.
}

Segundo Montanari e Pilatti (2009) a necessidade de um entendimento maior acerca do estilo de trabalhar em grupo é, perante do crescente uso da gestão fundamentada em equipes, essencial para formação e reestruturação de equipes no ambiente produtivo. Dessa forma, cada vez mais, ela precisa ir além das diárias adversidades e motivar conhecimentos 
para a solução de problemas.

Hersey e Blanchard (1986, p.196-197) afirmam que "uma liderança eficaz exige comportamentos e habilidades, que podem ser adquiridos por meio de desenvolvimento gerencial e experiência no trabalho".

Oliveira (2006, p. 13) ressalta "as qualidades pessoais de liderança, como sendo um conjunto de habilidades. Ela depende de um número de qualidades pessoais sutis que são difíceis de ver, mais que são muito poderosas". Assim, incluem comportamentos tais como entusiasmo, integridade, coragem e humildade.

Sobre o assunto acrescenta-se que liderança "é a tensão criada pelo fosso entre a situação presente e o sonho. Como toda tensão procura resolução, ela é fonte de energia que leva à criação de algo que não existe. E é isso que fazem os líderes" (SENGE, 1998, p. 6).

O líder assume um importante papel de facilitador dos colaboradores, sanando-os de suas fraquezas e proporcionando condições/ferramentas para que os mesmos utilizem da melhor forma as suas habilidades. Nesse sentido, os lideres dentro das organizações são o elo primordial no desempenho da mesma, pois são tidos como moderadores de desempenho na organização uma vez que buscam aumentar os valores coletivos (ROSA, 2011).

Rosa (2011, p.2) acrescenta ainda que:

Como vantagem competitiva essencial do futuro, o fator liderança terá importância e responsabilidade pelo desenvolvimento de uma visão condizente com a realidade, pela criação de estratégias para implementar essa visão, pela comunicação efusiva da visão no sentido de conquistar adeptos a ela, pela delegação de poder às pessoas que estão ao seu redor e, pelo depósito de confiança nas pessoas para que possam criar e implementar aquela visão.

Em consonância a isso, Hunter (2006, p. 20), afirma:

\begin{abstract}
Liderar significa conquistar as pessoas, envolvê-las para que coloquem sua mente, coração, criatividade e excelência a serviço de um objetivo, fazendo com que se empenhem ao máximo nessa missão. Então liderar, inspirar e influenciar pessoas a fazerem a coisa certa, visando atingir os objetivos e a missão da organização.
\end{abstract}

Sem bons líderes as organizações serão incapazes de lidar com as constantes mudanças que são necessárias para sobreviver e competir eficazmente no mundo dos negócios. Muitas mudanças sempre demandam mais liderança. Essas diferentes funções entre lidar com complexidade e lidar com mudanças compõem as atividades do administrador/líder.

A liderança é definida como fenômeno complexo, o líder é a pessoa que tem viabilidade 
de influenciar outros no trabalho ou em qualquer atividade na comunidade (KWASNICKA,2007).

Na visão de Kotter (1997), um líder tem como principal atividade a produção de mudança, com sua ação pautada sobre três dimensões fundamentais: estabelecer a direção estratégica da empresa, comunicar essas metas aos recursos humanos e motivá-los para que sejam cumpridas

Os líderes são responsáveis pela gestão de algumas pessoas na organização como um todo, logo eles tendem a ser responsáveis de certa forma pela manutenção de um ambiente de qualidade e pelo alcance dos resultados. A Liderança é responsável por gerir e justapor a energia das pessoas, assim ela cria um objetivo comum para todos e faz a sinergia das atividades de cada um (VIEIRA, 2011).

Charan (2008) aponta que uma liderança forte acarreta uma organização mais forte, assim uma liderança fraca diminui o potencial da organização. Os maus líderes tornam os liderados desmotivados se isso perdurar por muito tempo gera uma situação de difícil reversão, devido a isso a liderança impacta na motivação das pessoas dentro da empresa o que afeta o clima organizacional.

Sob o ponto de vista clássico da administração, o líder tem a função de estabelecer e fazer cumprir critérios de desempenho com o intuito de alcançar objetivos organizacionais; e sua atenção principal centralizava-se na necessidade da organização e não nas necessidades do indivíduo (STONER; FREEMAN, 1999).

Liderança é um processo continuo de escolha que permite ao grupo caminhar em direção à sua meta apesar de todas as perturbações internas e externas. O grupo tende a escolher como líder a pessoa que pode lhe dar mais assistência e orientação. A liderança é uma questão de redução da incerteza do grupo. O líder é um tomador de decisões ou aquele que ajuda o grupo a tomar decisões adequadas. O líder assume um papel preponderante, dentro de um grupo quer seja como facilitador ou proporcionando condições para que o grupo desempenhe suas atividades da melhor forma. Liderar significa conquistar pessoas, despertar-lhes os valores de criatividade e excelência a serviço de um objetivo e missão de uma organização (CHIAVENATO, 2000).

Para Bennis (1996, p. 78), “a presença do líder é importante para a eficácia das organizações, para as frequentes turbulências e mudanças do ambiente e para a integridade das instituições".

Segundo Drucker (1967 apud SOUZA, 2011) liderar é ter imaginação, conhecimento e inteligência, e somente sua eficácia e empenho no desenvolvimento das atividades ao líder atribuídas poderão converter estas qualidades em resultados. Pois, o conhecimento e inteligência sem ação não são capazes de tornar o profissional um líder, sendo necessários para tanto, habilidades, conhecimentos e competência no desenvolvimento do papel de líder. 
Conforme Souza (2011) Liderança consiste em um processo contínuo de motivar todos os envolvidos nas atividades individuais e grupais de forma a atingir o resultado esperado. Dessa forma, liderança é uma competência de caráter vincular, ou seja, existe uma relação entre duas ou mais pessoas, fundamentada no exercício da influência e motivação constante.

\subsection{A influência da liderança na motivação da equipe}

Segundo Chiavenato (2001, p.157) "A influência é uma forma psicológica, uma transação interpessoal na qual uma pessoa age de modo a modificar o comportamento de outra, de algum modo intencional [...]”.

Sendo assim, a influência envolve conceitos como poder e autoridade, maneiras pelas quais se provocam mudanças no comportamento de pessoas ou de grupos sociais, pode-se diferenciar poder e autoridade como sendo:

a) O poder é o potencial de influência de uma pessoa sobre outra; é a capacidade de exercer influência, embora isso não signifique que essa influência seja realmente exercida. A autoridade é o poder legitimo, isto é, o poder que tem uma pessoa em virtude do seu papel ou posição em uma estrutura organizacional. E, portanto, o poder legal e socialmente aceito (CHIAVANATO, 2001, p.157).

De acordo com Guimarães (2002), a liderança se baseia na capacidade de influenciar as pessoas em diferentes situações e contextos, ocorrendo em grupos de diversos segmentos, onde o processo de comunicação entre as pessoas funciona como norte para a consecução dos objetivos almejados; e o papel da liderança nas organizações compreende a articulação das necessidades demandadas das orientações estratégicas em sintonia com as necessidades dos indivíduos, orientando as necessidades de ambas as partes na direção do desenvolvimento institucional e individual, para ser exercida com excelência, estimulando o comprometimento dos indivíduos, conduzindo-os a altos desempenhos, e gerando resultados positivos crescentes para a organização.

No entanto Chiavenato (1993, p. 177) descreve teorias que analisam a liderança em termos de estilos de comportamento do líder em relação aos seus subordinados. São as formas pelas quais o líder desempenha sua influência. O estudo que explica a liderança por meio de estilos de comportamento, sem se preocupar com características de personalidade, nos leva a três estilos de liderança: autocrática, liberal (laissez-faire) e democrática.

Consequentemente cabe ao líder escolher o tipo que mais condiz com a sua personalidade ou com o tipo de organização que se combina mis os estilos de liderança, Chiavenato (2001, p. 161) descreve cada uma da seguinte maneira: 
Liderança autocrática: Na liderança autocrática o líder é focado apenas nas tarefas. Este tipo de liderança também é chamado de liderança autoritária o líder toma as decisões sem a participação do grupo, o trabalho só e desenvolvido com a presença do líder, o gera frustração, agressividade entre os colaboradores. Liderança democrática: liderança participativa ou consultiva, este tipo de liderança é voltado para as pessoas e há participação dos liderados no processo decisório as atividades são discutidas entre os líderes e os liderados proporcionando um ambiente mais agradável, amigável, o líder necessariamente não precisa estar presente para que os liderados executem suas tarefas.

Liderança liberal ou laissez-faire: liderança liberal significa literalmente "deixai fazer, deixai ir, deixai passar". Neste tipo de liderança as pessoas têm mais liberdade na execução dos seus projetos, a equipe e deixada totalmente à vontade indicando possivelmente uma equipe madura, não a necessita de supervisão constante. Por outro lado, a liderança liberal também pode ser indício de uma liderança negligente e fraca, onde o líder deixa passar falhas e erros sem corrigi-los, tais influências refletem diretamente no desempenho do trabalho dos liderados uma vez que o líder precisa ter em mente que é preciso fazer as coisas simples antes de tentar planos mirabolantes de motivação.

Segundo French e Raven (1959, p. 157 apud SANTOS et al.,2007), a chave para a supervisão é a influência. A influência que um supervisor pode exercer em um subordinado é determinado pelo tipo de poder que ele demonstra ter, eles indicam cinco tipos de poder:

Poder coesivo: provém da habilidade do supervisor em aplicar ou não ao subordinado alguma punição, dependendo do seu comportamento.

Poder de recompensa: provém da habilidade do supervisor de dar algum reconhecimento ao subordinado por seu trabalho.

Poder de sabedoria: provém da crença do subordinado de que o supervisor tem o conhecimento ou habilidade de executar as tarefas de modo superior aos demais.

Poder pela identificação: resulta da identificação do subordinado com o chefe e do uso dessa identificação como referência para definir seu próprio comportamento.

Pode legal: origina-se da crença do subordinado de que o supervisor possui esse poder legal oriundo da posição que ele ocupa.

O líder tem como características importantes o conhecimento sobre a atividade que está realizando, relacionamento interpessoal, que gera vínculo com seus subordinados e consegue manter o equilíbrio emocional gerando um foco no resultado (BARRETO; PEREIRA, 2007).

Empresas que possuem programa de desenvolvimento consistente e voltado para o resultado da organização, tendem a gerar um objetivo positivo na organização como um todo. As organizações que possuem programas estruturados de treinamentos, tanto para lideres quanto para os seus subordinados, conseguem alinhar melhor os valores e a missão com todos. Investir no desenvolvimento dos líderes constitui, também, focar na 
qualidade dos produtos e serviços, ou seja, um líder preparado conseguem coordenar melhor as suas equipes impactando o resultado positivamente (VIEIRA, 2011).

Com relação ao paradoxo entre o liderar e gerenciar, Rowe (2002, p.18) menciona que:

[...] um líder estratégico cria a desordem, comete erros e, às vezes, é repreendido por seus chefes e subordinados, precisando até desculpar-se com os funcionários por ter criado muita desordem sem que eles estivessem preparados para isso. Entretanto, as recompensas valem a pena, visto que as pessoas que trabalham com esse líder apresentam um aumento em termos de energia e produtividade, realizando mais tarefas em um tempo menor. Eles têm mais prazer no trabalho, tornando-se mais criativos, inovadores e mais propensos a correr riscos, pois sabem que isso aumentará a viabilidade em longo prazo.

O perfil do líder diferencia muito do papel de gerente ou chefe, enquanto este, centraliza e delega, o líder não possui postura de executor e sim de servidor. Suas atribuições deixam de ser: comandar, controlar e executar, passando a ser: delegar, debater, ouvir sugestões, compartilhar objetivos, informar, apoiar etc. Sendo assim, o objetivo deste trabalho é analisar os impactos positivos que a liderança gera sobre o liderado, com isso contribuindo para sua produtividade e/ou lucratividade (BUENO, 2011).

\section{Metodologia}

A Metodologia utilizada visa esclarecer às técnicas adotas para seleção de amostras e coletas de dados para comprovação dos impactos positivos da liderança no processo produtivo. Por sua vez, Gil (2002), define metodologia como relatório que deverá esclarecer acerca das técnicas adotadas para seleção da amostra e coleta de dados. E investigar como cada liderado descrevia os pontos positivos dos líderes em gestão.

Todo trabalho está voltado para as características administrativas relativas à empresa na área da organização, da qualidade e lucratividade, focando o papel do líder e das chefias, traçando uma analogia quanto aos papeis de ambos, explicando detalhadamente o papel do líder sua influência para com os colaboradores, ou seja, delineando o impacto positivo da liderança no processo produtivo.

Com isso, no projeto em questão, as pesquisas utilizadas foram: as pesquisa bibliográfica, quantitativa, qualitativa e levantamento técnico.

De acordo com Gil (2002), "a pesquisa bibliográfica obtém os dados a partir de trabalhos publicados por outros autores, como livros, obras de referência, periódicos, teses e dissertações e a pesquisa de levantamento: analisa comportamento dos membros de uma população por meio da interrogação direta a uma amostra de pessoas desta população". Foi realizada a analise com base em livros e bibliografias condizentes com o tema, trabalhos publicados, revistas. 
A pesquisa bibliográfica foi realizada por meio de consultas em site de revistas e anais de congressos com os temas sobre liderança ou gestão, também foram consultados livros disponíveis na biblioteca da Faculdade Funorte ou livros adquiridos pelos próprios pesquisadores.

No entendimento de Marconi e Lakatos (2011, p.269), "A metodologia qualitativa, preocupa-se em analisar e interpretar aspectos mais profundos, descrevendo a complexibilidade do comportamento humano".

Ainda conforme Marconi e Lakatos (2011, p.269) a metodologia qualitativa "fornece análise mais detalhada sobre as investigações, hábitos, atitudes, tendências de comportamento e etc".

Na pesquisa quantitativa, através da mensuração das variáveis busca-se verificar a influência destas sobre outras variáveis, assim, têm-se como características principais a análise de dados por meio de estatística, além do alto índice de generalização e um papel neutro do pesquisador, ao passo que este não interfere no fenômeno estudado (APPOLINÁRIO, 2012). Em relação a este tema, Marconi e Lakatos (2011, p.4) esclarecem que o pesquisador "não deve fazer juízo de valor, mas deixar que os dados e a lógica levem à solução real".

Ainda segundo Gil (2002), o levantamento de dados caracteriza-se pela interrogação direta das pessoas, cujo comportamento se deseja conhecer. Na realidade e um levantamento de dados através de um grupo de pessoas acerca do problema estudado para, em seguida, mediante análise quantitativa, obter as conclusões correspondentes aos dados coletados.

Portanto, o levantamento de dados foi realizado por meio de questionários e entrevistas aplicados junto aos colaboradores sobre o tipo de liderança, onde fizemos as comparações com base nos dados coletados, do faturamento, e se estes estão diretamente relacionado com o índice de produtividade.

Segundo Silva (2008), questionário é um conjunto ordenado que consistente em perguntas a respeito de várias situações que se deseja descrever, assim, é possível visualizar o questionário elaborado para operacionalização do estudo no apêndice A.

Por sua vez, Oliveira (1997) aponta que o método quantitativo é empregado no desenvolvimento de pesquisas descritivas de âmbito social, econômico, de comunicação, mercadológicas e de administração e representa uma forma de garantir a precisão dos resultados, evitando distorções.

As entrevistas foram realizadas em 2 empresas no ramo metalúrgico de Montes Claros, sendo empresa Beta com total 18 colaboradores, e empresa Alfa com 28 colaboradores 
totalizando 48 colaboradores. A presente pesquisa não foi realizada por meio de amostra, uma vez que seu universo é pequeno.

Para Ganga (2012) em casos em que a população é muito pequena (tamanho da população $\mathrm{N}$ menor que 500), não se faz necessário a utilização de cálculos amostrais, mas caso se opte por realizar os cálculos a amostra pode ser formada por $50 \%$ da população.

Foi aplicado um questionário semi-estruturado, com questões fechadas específicas e uma entrevista para cada colaborador. Os proprietários das empresas nos concederam um tempo para a explicação aos colaboradores do motivo da aplicação do questionário e da entrevista, e o seu objetivo principal. Sendo assim, os questionários foram respondidos e devolvidos ao aplicador. Todos os dados foram analisados e tabulados no programa Microsoft Excel.

Este estudo é de caráter exploratório, com abordagem quanti-qualitativa, desenvolvido através de pesquisa de campo. Foram também realizadas pesquisas bibliográficas, por meio de livros, sites, artigos de forma a definir conceitos que provassem a viabilidade e a necessidade do estudo.

\section{Resultados e discussão}

\subsection{Perfil socioeconômico dos funcionários}

Os dados coletados na empresa Alfa e Beta serão aqui apresentados e discutidos com o intuito de alcançar os objetivos propostos nesta pesquisa.

Inicialmente, buscou-se traçar o perfil socioeconômico dos funcionários das empresas pesquisada. Os dados coletados estão representados em quadros de acordo com o que foi coletado em cada empresa.

Na empresa Alfa foram entrevistados 28 funcionários e na empresa Beta 18 em relação ao estado civil. Obteve-se os seguintes dados.

Quadro 1 - Estado civil dos funcionários

\begin{tabular}{|l|l|l|}
\hline & Empresa Alfa & Empresa Beta \\
\hline Solteiro & $50 \%$ & $50 \%$ \\
\hline Casado & $36 \%$ & $39 \%$ \\
\hline Outros & $14 \%$ & $11 \%$ \\
\hline
\end{tabular}

Fonte: Autoria própria (2014). 
Percebe-se que em ambas as empresas 50\% dos funcionários são solteiros e que uma porcentagem próxima de funcionários são casados sendo 36\% na empresa Alfa e 39\% na empresa Beta. Os funcionários que não são nem casados nem solteiros são $14 \%$ da empresa Alfa e 11\% na empresa Beta.

Os dados referentes a escolaridade dos funcionários das empresas pesquisadas estão sintetizados no quadro 2 .

Quadro 2- Escolaridade dos funcionários

\begin{tabular}{|lcc|}
\hline & Empresa Alfa & Empresa Beta \\
\hline Ensino Fundamental Incompleto & $4 \%$ & $28 \%$ \\
\hline Ensino Fundamental Completo & $14 \%$ & $0 \%$ \\
\hline Ensino Médio Incompleto & $11 \%$ & $44 \%$ \\
\hline Ensino Médio Completo & $50 \%$ & $28 \%$ \\
\hline Ensino Superior Incompleto & $14 \%$ & $0 \%$ \\
\hline Pós Graduação & $7 \%$ & $0 \%$ \\
\hline
\end{tabular}

Fonte: Autoria própria (2014).

Observa-se que na empresa Alfa metade $50 \%$ dos funcionários possuem ensino médio completo e ninguém possui pós graduação. Na empresa Beta $44 \%$ possui como escolaridade o ensino médio incompleto e ninguém possui graduação ou pós graduação.

Também foi questionado aos funcionários sobre a renda familiar que possuem, sendo os dados transcritos para o quadro 3.

Quadro 3 - Renda familiar dos funcionários

\begin{tabular}{|c|c|c|}
\hline & Empresa Alfa & Empresa Beta \\
\hline 1 salário mínimo & $11 \%$ & $11 \%$ \\
\hline 1,5 salários mínimos & $32 \%$ & $11 \%$ \\
\hline 2 salários mínimos & $40 \%$ & $22 \%$ \\
\hline 2,5 salários mínimos & $3 \%$ & $17 \%$ \\
\hline 3 salários mínimos & $3 \%$ & $28 \%$ \\
\hline 4 salários mínimos & $3 \%$ & $5,5 \%$ \\
\hline Mais de 4 salários mínimos & $8 \%$ & $5,5 \%$ \\
\hline
\end{tabular}

Fonte: Autoria própria (2014).

Na empresa Alfa a maioria $40 \%$ tem renda familiar de 2 salários mínimo e na empresa Beta a maioria possui renda familiar de 3 salários mínimos.

Evidencia-se que o perfil dos funcionários entrevistados é de pessoas com baixa renda e com pouca escolaridade, sendo a maioria casado e com filhos. 
Em relação ao tempo de trabalho nas empresas, os funcionários entrevistados declararam os seguintes dados, sintetizados no quadro 4.

\begin{tabular}{lcc}
\multicolumn{3}{c}{$\begin{array}{c}\text { Quadro 4- Tempo de atuação na empresa } \\
\text { Empresa Alfa }\end{array}$} \\
\hline 0 a 5 anos & $86 \%$ & $45 \% \%$ \\
\hline 6 a 10 anos & $14 \%$ & $33 \%$ \\
\hline 11 a 15 anos & $0 \%$ & $17 \%$ \\
\hline 15 a 20 anos & $0 \%$ & $5 \%$ \\
\hline Mai de 20 anos & $0 \%$ & $0 \%$
\end{tabular}

Fonte: Autoria própria (2014).

Em ambas empresas percebe-se que a maioria dos funcionários atuam na empresa em até 5 anos. Na empresa Beta $5 \%$ dos funcionários tem até 20 anos de atuação na empresa, sendo um número significativo de profissionais com experiência.

\subsection{Avaliação da liderança}

Foi solicitado aos funcionários que avaliassem a liderança da sua empresa, dando nota de 1 a 5 sendo 1-Péssimo, 2-Ruim, 3-Bom, 4-Ótimo e 5-Excelente.

\subsubsection{Conforto em conversar com o líder: Atual x Anterior}

Na empresa Alfa, ao se comparar o conforto sentido pelos funcionários ao conversar com o líder percebe-se que $31 \%$ dos funcionários consideram o diálogo ruim, enquanto que $18 \%$ consideram o diálogo bom e outros $25 \%$ e $21 \%$ consideram ótimo e excelente respectivamente. Destaca-se que apenas $4 \%$ dos funcionários consideram o diálogo ruim entre funcionário e liderança. De maneira geral, observa-se nesta avaliação que o diálogo entre liderança e funcionários é satisfatório já que $65 \%$ dos funcionários avaliam entre bom e excelente o conforto em conversar com o líder atual.

Em relação ao líder anterior, percebe-se que $18 \%$ dos funcionários consideram que o conforto em conversar com ele era ruim, enquanto que 7\% considerou como bom, $43 \%$ considerou ótimo e 32\% considerou excelente. Nota-se que o diálogo entre liderança e funcionários de uma forma geral é considerado ótimo, já que $75 \%$ dos funcionários avaliaram como ótimo ou excelente o conforto em conversar com a liderança anterior.

Ao se traçar um paralelo entre as lideranças, observa-se que a liderança anterior teve uma maior aceitação dos funcionários em relação a liderança atual o que mostra que o líder anterior possuía uma capacidade de comunicação maior o que certamente facilitava sua gestão. 
$\mathrm{Na}$ empresa Beta, $78 \%$ dos funcionários avaliou o conforto em conversar com líder ótimo e $22 \%$ avaliou como excelente. Sendo assim, é nítido que o líder atual desenvolve boa comunicação com os funcionários.

Em relação ao líder anterior 6\% dos funcionários avaliaram o conforto em conversar com ele como péssimo, enquanto que $39 \%$ avaliou como ruim, $44 \%$ como bom, $11 \%$ como ótimo e nenhum avaliou como excelente. Neste caso, nota-se que a avaliação dos funcionários em relação ao líder anterior está equilibrada já que $45 \%$ dos funcionários avalia como péssimo ou ruim e outros $55 \%$ restantes avalia como bom e ótimo. Nota-se que embora a maioria considere confortável conversar com a liderança anterior é significativo a quantidade de funcionários que consideravam como ruim ou péssimo.

Diante destes resultados, percebe-se que na empresa Alfa o líder anterior teve uma melhor avaliação que o líder atual no entanto, sua avaliação não foi ruim. Já na empresa Beta o líder atual obteve melhor avaliação.

Neste sentido, é importante frisar que liderar é conseguir que as coisas sejam feitas através das pessoas, porém sempre haverá duas dinâmicas em jogo: tarefa e relacionamento. Um bom líder é aquele capaz de contribuir com as outras pessoas, que seja capaz de conhecer suas necessidades individuais, olhar seus objetivos e desempenho. Para tanto, é necessário estabelecer uma comunicação eficaz, desenvolver um bom trabalho em equipe e auto desenvolvimento, além de contribuir para o desenvolvimento dos outros (SOUZA, 2011).

\subsubsection{O líder leva em consideração a opinião do funcionário: Atual x Anterior}

Ao avaliar se o líder leva em consideração a opinião dos funcionários, o líder atual da empresa Alfa foi avaliado por $18 \%$ dos funcionários como ruim, por $46 \%$ como bom e por $25 \%$ e $11 \%$ como ótimo e excelente respectivamente.

Já o líder anterior foi avaliado pelos funcionários como 4\% péssimo, $0 \%$ ruim, 54\% bom, $21 \%$ ótimo e $21 \%$ excelente.

Na empresa Beta 17\% avaliaram bom como líder atual levar em consideração a opinião dos funcionários, e $33 \%$ e $50 \%$ avaliaram como ótimo e excelente respectivamente.

O líder anterior da empresa Beta foi avaliado como bom em levar em consideração a opinião dos funcionários por $6 \%$ dos funcionários, enquanto que $61 \%$ avaliou como ótimo e $33 \%$ como excelente.

No quesito levar em consideração a opinião dos funcionários, percebeu-se que na empresa Alfa tanto o líder anterior quanto o atual estão avaliados como bom ou ótimo de maneira geral. 
Em contrapartida a avaliação dos líderes da empresa Beta pode ser considerada como ótima ou excelente, sendo que nenhum dos líderes foi avaliado como ruim ou péssimo.

Ao ser ouvido o funcionário sente-se motivado, pois percebe que é um membro importante da empresa. Sobre isso, Bergamini (1994, p.40) esclarece afirma:

\footnotetext{
Sendo assim, a chave do sucesso da liderança é executar as tarefas enquanto se constroem bons relacionamentos. O líder precisa saber perceber as motivações dos colaboradores e expectativas destes, no ambiente de trabalho, saber trabalhar com as diferenças motivacionais de cada um, compreendendo o estilo próprio de cada colaborador.
}

Portanto, é fundamental saber respeitar as opiniões das pessoas dentro do ambiente organizacional. Saber prestar atenção ao que dizem, e deixar claro que podem contar com amparo da organização, se necessário. Desta forma, surgem profissionais que passam a perceber que têm importância, que suas opiniões são válidas, construindo a democracia e o conhecimento por parte de todos colaboradores dos reais objetivos organizacionais (MAINARDES, 2010).

\subsubsection{Como o líder atual lhe trata: Atual x Anterior}

Para $43 \%$ dos funcionários o líder os tratam de maneira boa, enquanto que 39\% e 18\% afirmam que o tratamento é ótimo e excelente, respectivamente.

Em relação ao tratamento do líder anterior, $46 \%$ dos funcionários afirmaram que eram tratados de maneira ótima e 54\% afirmaram que eram tratados de maneira excelente pelo antigo líder da empresa Alfa.

$\mathrm{Na}$ empresa Beta $6 \%$ dos funcionários considerou o tratamento do líder atual como péssimo, já $67 \%$ avaliou como bom e $28 \%$ avaliou como ótimo.

O líder anterior foi avaliado em relação ao seu tratamento oferecido para os funcionários como ruim por $22 \%$, como bom por $28 \%$ e como ótimo por $50 \%$ dos funcionários.

Percebe-se que na empresa Alfa os funcionários avaliam ser bem tratados pelo líder atual, no entanto, o líder atual recebeu uma avaliação melhor já que mais da metade dos funcionários consideraram que recebiam excelente tratamento por parte dele.

Na empresa Beta o líder anterior foi melhor avaliado pelos funcionários sendo considerado por $50 \%$ como um líder que trata excelentemente seus funcionários, o líder atual foi avaliado de maneira geral como bom no tratamento que oferece para os funcionários. 


\subsubsection{O líder te ajuda quando você o solicita: Atual x Anterior}

No quesito ajuda quando necessário, o líder atual da empresa Alfa foi avaliado como ruim por $29 \%$ dos funcionários, como bom por $54 \%$ e como ótimo por $18 \%$.

Já o líder anterior foi avaliado como bom por $14 \%$ dos funcionários e como ótimo e excelente por $36 \%$ e $50 \%$ dos funcionários respectivamente.

Na empresa Beta 17\% dos funcionários avaliaram como bom o líder atual, enquanto que $39 \%$ avaliaram como ótimo e $44 \%$ como excelente.

Em relação ao líder anterior foi avaliado por $22 \%$ como ruim, por $39 \%$ como bom e $33 \%$ e $6 \%$ como ótimo e excelente respectivamente.

Nota-se que na empresa Alfa o líder atual foi melhor avaliado no quesito ajuda quando necessário enquanto que na empresa Beta o líder atual foi melhor avaliado sendo considerado como excelente a sua ajuda quando necessário por $44 \%$ dos funcionários.

Os líderes são agentes de mudança, pelas suas capacidades de fazerem as coisas acontecerem. O líder é responsável em catalizar as energias de um grupo para a conquista e superar desafios. Um verdadeiro líder é capaz de perceber a necessidade do grupo e responder adequadamente a ela, sendo considerado símbolo do desejo coletivo (PREDEBON ,1999).

Assim percebe-se a necessidade de que o líder esteja disposto a auxiliar os funcionários quando necessário, pois, assim, torna-se possível conseguir alcançar os objetivos da empresa, uma vez que todos buscam o sucesso da organização em que estão inseridos.

\subsubsection{Qual a sua avaliação a respeito do líder: Atual x Anterior}

Na empresa Alfa, $7 \%$ dos funcionários avaliou o líder atual como ruim, $68 \%$ como bom e $25 \%$ como ótimo.

Já em relação ao líder anterior $4 \%$ avaliou como bom, $82 \%$ como ótimo e $14 \%$ como excelente.

$\mathrm{Na}$ empresa Beta os funcionários avaliaram o líder atual em $6 \%$ como bom, $28 \%$ como ótimo e $67 \%$ como excelente.

O líder anterior da empresa Beta foi avaliado 39\% como bom, 50 como ótimo e $11 \%$ como excelente.

Com efeito, os estudos de Salas, Sims e Burke (2005) incluem a liderança como um dos grandes cinco contributos para a eficiência de uma organização, através da performance 
das equipes de trabalho.

Partindo disso, observa-se que na empresa Alfa o líder anterior foi melhor avaliado que a maioria, $82 \%$ dos funcionários avaliou o líder como ótimo.

No entanto, na empresa Beta o líder atual foi melhor avaliado sendo que $67 \%$ dos funcionários avaliou o líder como excelente.

\subsubsection{Como você avalia o comportamento do líder: Atual x Anterior}

O comportamento do líder atual da empresa Alfa foi avaliado como ruim por $18 \%$ dos funcionários, como bom por $25 \%$ dos funcionários e como ótimo por $57 \%$ dos funcionários.

Já o comportamento do líder anterior foi avaliado como bom por $7 \%$ dos funcionários, como ótimo por $61 \%$ dos funcionários e como excelente por $32 \%$ dos funcionários.

$\mathrm{Na}$ empresa Beta o comportamento do líder atual foi avaliado como bom por $6 \%$ dos funcionários, como ótimo por $22 \%$ dos funcionários e como ótimo por $72 \%$ dos funcionários.

O líder anterior da empresa Beta foi avaliado pelo seu comportamento como bom por $78 \%$ dos funcionários, como ótimo por $17 \%$ e como excelente por $6 \%$ dos funcionários.

Com base nessas informações, percebe-se que na empresa Alfa o líder anterior foi melhor avaliado sendo considerado por $32 \%$ dos funcionários como excelente.

Já na empresa Beta o líder atual foi melhor avaliado sendo que $72 \%$ dos funcionários considerou o comportamento do líder atual como excelente enquanto que o líder anterior foi avaliado por apenas $6 \%$ dos funcionários como um excelente comportamento.

Os líderes inspiram os seus seguidores a transcender os seus próprios interesses em prol da organização, sendo capazes de causar um efeito profundo e extraordinário sobre os seus seguidores (ROBINS, 2007).

Assim, o comportamento do líder é capaz de inspirar os demais funcionários para que a busca por resultados positivos na organização seja constante. 


\subsection{Entrevista com os funcionários}

\subsubsection{Como você descreve seu líder atual}

Os funcionários da empresa Alfa descreveram o líder atual como "inexperiente", "fechado para conversa" e "ignorante". Por outro lado, descrevem o líder anterior como "atencioso", "técnico", "capacitado", "experiente", pontual e criativo.

$\mathrm{Na}$ empresa Beta, os funcionários descreveram o líder atual como "perfeccionista", "técnico", "companheiro", "direto" e "proativo" e o líder anterior como "impaciente" e como uma pessoa que "cobra e não faz".

Percebe-se que os funcionários da empresa Alfa consideram o funcionário anterior como mais positivo que o atual e nota-se também uma certa rejeição por parte dos funcionários em relação ao atual líder da empresa.

\subsubsection{Como você descreve as principais características positivas dos líderes}

Os funcionários da empresa Alfa descreveram o líder atual como "bom companheiro de trabalho", "legal" e "satisfatório" e o líder anterior como "eficiente" que "resolvia os problemas com facilidade" e que tinha "boa comunicação com todos".

Na empresa Beta os funcionários destacaram como principais características do líder atual "paciência", "preocupação com os colaboradores", "comunicativo" e o líder anterior como "sobrecarregado" e que não "intervia nos serviços".

Nota-se que os colaboradores da empresa Alfa descreveram o líder atual como um bom companheiro e destacaram a qualidade da comunicação do líder anterior, no entanto os funcionários da empresa Beta destacam as qualidades do líder atual e não descreveram qualidades para o líder anterior.

\subsubsection{Como você descreve as principais características negativas dos líderes}

Os funcionários da empresa Alfa descreveram como características negativas do líder atual "não é proativo", "muito calado e que não aceita opiniões". E descreveu como características negativas do líder negativa do líder anterior como "muito exigente".

Já os funcionários da empresa Beta descreveram as características negativas do líder atual "intervenção nos serviços" e "muito exigente", em relação ao líder anterior foi respondido que ele "não aceitava opiniões" e "chamava a atenção na frente de outros colaboradores". 
Ficou nítido que a não aceitação de opiniões ou falta de comunicação são as principais características negativas destacadas pelos funcionários da empresas Alfa e Beta, tanto para o líder atual como para o líder anterior.

\subsubsection{Qual o líder que mais o motivava a trabalhar/produzir? E como o motivava?}

$\mathrm{Na}$ empresa Alfa os funcionários afirmaram que o líder que mais os motivava foi o líder anterior e que para isso ele "motivava", "trabalhava junto com a equipe" e era "muito educado"

$\mathrm{Na}$ empresa Beta, os funcionários afirmaram que o líder que mais os motiva a trabalhar/produzir é o líder atual e que para isso ele dá "prêmio de produtividade", "combina dia de folga", ou seja é flexível, "transmite elogios dos clientes" e utiliza "material de qualidade".

Mais uma vez é nítido que o líder anterior é melhor visto pelos funcionários na empresa Alfa e que o líder atual tem mais credibilidade dos funcionários da empresa Beta.

\subsection{Impacto da liderança na organização}

Com base nas análises realizadas e a busca de informações juntos as empresas pesquisadas, evidencia-se que a liderança quando é bem desenvolvida existe um impacto positivo na organização.

Um bom líder consegue motivar os demais funcionários da empresa aumentando a produtividade dos mesmos, isso ficou nítido nesta pesquisa, uma vez que a empresa Alfa fatura com a liderança atual $52 \%$ e com a liderança anterior faturava $87 \%$, sendo evidente que a liderança considerada pelos funcionários como melhor preparada é responsável pelo maior faturamento da empresa.

A empresa Beta possui uma liderança atual bem aceita pelos funcionários que o consideram de maneira geral como um líder exemplar e isso também reflete no faturamento da empresa que atualmente fatura $76 \%$ enquanto que no passado este faturamento chegava a apenas $48 \%$.

Assim, entende-se que de acordo com o estilo de liderança, um líder pode impactar positivamente (incentivando o desenvolvimento da criatividade) ou negativamente (bloqueando a capacidade criativa de sua equipe) (SOUZA, 2011).

\section{Conclusões}

A liderança nas organizações tem sua relevância evidenciada quando é considerado o ambiente organizacional, uma vez que uma liderança bem desempenhada é capaz de transformar o clima da organização fazendo com que a equipe torne-se motivado. 
Ao longo da pesquisa, tornou-se nítido o quão importante é a comunicação no ambiente empresarial e que a comunicação entre liderança e liderados é considerada essencial para o desenvolvimento adequados das tarefas no trabalho.

Uma liderança bem desenvolvida em que existe comunicação, companheirismo e acima de tudo motivação é capaz de obter resultados positivos para a empresa como pode ser percebido através dos relatos dos funcionários e dos resultados financeiros das empresas em que foi realizada a pesquisa.

Evidenciou-se que os funcionários sentem-se motivados com o fato de o líder ouvi-los. Ao serem aceitas as opiniões dos funcionários da equipe estes sentem-se valorizados e sentemse parte importante da empresa o que faz com que a motivação para o trabalho aumente e consequentemente os resultados da equipe melhorando, sendo este um impacto positivo da liderança na organização.

Portanto, o líder, tem um papel fundamental sobre isso a motivação e crescimento do capital humano das empresas, pois é ele o responsável para esse apoio, por isso a importância de suas atitudes, uma vez que ela impacta diretamente em seu liderado.

\section{Referências}

- APPOLINÁRIO, Fábio. Dicionário de metodologia científica: um guia para a produção do conhecimento científico. São Paulo-SP: Atlas, 2012, 300p.

- $\quad$ ARRUDA, A.M.F; CRISÓSTOMO, E. RIOS, S.S. A importância da liderança nas organizações. Ceará, 2012.

- BARRETO, M.B.B.; PEREIRA, S.L. A comunicação do líder como fator motivacional.2007. 91 f. Trabalho de Conclusão de Curso (Pós-Graduação em Gestão Estratégica de Pessoas). Fundação Instituto de Administração. Brasília, 2007.

- BENNIS, Warren. A formação do líder. São Paulo: Atlas, 1996.

- BEUREN, Ilse Maria; RAUPP, Fabiano Maury. Metodologia da pesquisa aplicável às ciências sociais. In: BEUREN, Ilse Maria (org). Como elaborar trabalhos monográficos em contabilidade: teoria e prática. São Paulo: Atlas, 2008. p. 4675.

- BERGAMINI, C.W. Liderança: Administração do sentido. São Paulo: Atlas,1994. 
- BUENO, Valdemir. Impactos das atitudes negativas dos líderes sobre os liderados. Rev. Npi/Fmr. set. 2011. Disponível em: $<$ http://www.fmr.edu.br/npi.html> Acesso em: 20 de mai.2014.

- CHARAN, R. O líder criador de líderes. Rio de janeiro: Elsevier, 2008

- CHIAVENATO, Idalberto. Gestão de Pessoas. Rio de Janeiro: Elsevier,2006. Introdução à teoria geral da Administração. Rio de Janeiro: Editora Campus, 1993. Introdução à Teoria Geral da Administração. Rio de Janeiro, 2000. Teoria Geral da Administração. Rio de Janeiro: Campus, 2001

- CORREIA, Rui; MAINARDES, Emerson Wagner; LOURENÇO, Luis. A liderança transformacional como factor de Desenvolvimento na gestão pela qualidade total: Criatividade, inovação, confiança e trabalho em equipa.

Disponível em http://phdtree.org/pdf/51797206-a-lideranca-transformacionalcomo-factor-de-desenvolvimento-na-gestao-pela-qualidade-total-criatividadeinovacao-confianca-e-trabalho-em-equi/. Acesso em 29. Set. 14.

- DRUCKER, Peter. O gerente eficaz. Rio de Janeiro: Livros Técnicos Científicos, 1967.

- GIL, Antônio Carlos. Como Elaborar Projetos de Pesquisa. São Paulo: Atlas, 2008 .

Técnicas de pesquisa em economia e elaboração de monografias. $4^{\mathrm{a}}$ ed. São Paulo: Atlas, 2002.

- GUIMARÃES, Cláudia Patrícia Silvério Fragas. Liderança eficaz: pessoas motivadas e felizes, organizações saudáveis. São Paulo, 2002.

- HERSEY, Paul e BLANCHARD, Kenneth.Psicologia para administradores:a teoria e as técnicas da Liderança Situacional. Tradução de Edwino A. Royer. São Paulo: EPU, 1986.

- HUNTER, J. C. O Monge e o executivo: Uma história sobre a essência da Liderança. Rio de Janeiro: Sextante, 2006.

- KARMEL, P.H.; POLASEK, M.. Estatística Geral e Aplicada para Economistas, editora Atlas/MEC, $2^{\mathrm{a}}$ edição, 1974, p.106 - 224, São Paulo/SP.

- KOTTER, John P. Liderando mudança. Tradução de LeadingChange. Rio de Janeiro: Campus, 1997. 
- KWASNICKA, E. Lacava. Introdução à Administração. São Paulo: Atlas, 2007.

- MARCONI, Marina de Andrade; LAKATOS, Eva Maria. Técnicas de pesquisa: planejamento e execução de pesquisas, amostragens e técnicas de pesquisa elaboração, análise e interpretação de dados. $7^{\mathrm{a}}$ ed. $4^{\mathrm{a}}$ reimpr.,São Paulo-SP: Atlas, 2011.277p.

- MONTANARI, Robson Luiz; PILATTI, Luiz Alberto. A influência do estilo de trabalhar em grupo nos Processos de construção do conhecimento Organizacional. Revista Gestão Indústria, Universidade Tecnológica Federal do Paraná - UTFPR, ISSN 1808-0448 / v. 05, n. 01: p. 194-210, 2009.

- OLIVEIRA, A. C. Tecnologia de informação: competitividade e políticas públicas. Revista de Administração de Empresas, v. 36, n. 2, p. 34-43, 1996.

- OlIVEIRA, Silvio Luiz de. Tratado de Metodologia Científica. São Paulo: Pioneira, 1997.

- OLIVEIRA, Jayr Figueiredo de. Profissão líder: desafios e perspectivas. São Paulo:

- $\quad$ Saraiva, 2006.

- PEREIRA, Aline Soares; SCHMIDT, Alberto Souza. Análise da mudança organizacional de uma empresa Fumageira segundo a percepção da liderança: um estudo de caso. Revista Gestão Indústria, Universidade Tecnológica Federal do Paraná - UTFPR, ISSN 1808-0448 /. ISSN 1808-0448 / v. 04, n. 02: p. 34-47, 2008.

- REIS, P.N.C. O Impacto da Liderança na Construção da Cultura Organizacional: um Estudo de Caso Entre Alunos de uma Ies Privada. In: SEGET (Simpósio de Excelência e Gestão em Tecnologia).2012.

- REVISTA GESTÃO INDUSTRIAL. Diretrizes para autores: normas para publicação. Disponível em: https://periodicos.utfpr.edu.br/revistagi/information/authors. Acesso em: 15 out.2014.

- RICHARDSON, Roberto Jarry. Pesquisa social: métodos e técnicas. São Paulo: Atlas, 1989.

- ROSA, I.S.M. Liderança Organizacional: Mulheres Líderes nas Organizações Não Governamentais. Estudo de caso - OMCV.2011.48p.Monografia (Curso de Relações Públicas e Secretariado Executivo), Praia, 2011. 
- ROWE, W. Glenn. Liderança estratégica e criação de valor. ERA, Revista de Administração de Empresas, v. 42, n.1, p. 7-19, jan./mar. 2002.

- $\quad$ SANTOS, S. R. dos; MOREIRA, R. C. Liderança do Enfermeiro: Desafios da Prática. (Paraíba - $\mathrm{RN}$ ), 2006. Disponível em; http// www.uff.br/nepae/objn333santosetal.htm. Acesso em: 05/05/2014

- SANTOS, Jean Carlo Silva dos; ANTUNES, Elaine Di Diego. Relações de gêneros e liderança nas organizações: rumo a um estilo andrógino de gestão.2007. Disponível em seer4.fapa.com.br/index.php/arquivo/article/view/222. Acesso em 29. Set. 14.

- SENGE, Peter. A Quinta Disciplina: arte e prática da organização que aprende. Tradução de Regina Amarante. São Paulo: Best Seller, 1998.

- SILVA, Fabiula Meneguete Vides da; CUNHA, Cristiano José Castro de Almeida A transição de líder para contribuidor individual: um processo de perdas e ganhos. Disponível em www.unicesumar.edu.br/pesquisa/periodicos/index.php/.../2654/2322. Acesso em 29. Set. 14.

- SILVA, Carlos Ribeiro. Metodologia da pesquisa Aplicada a contabilidade. 2. Ed. São Paulo: Editora Atlas, 2008.

- SOUZA, L.R.S. Liderança: Impactos positivos e negativos sobre o potencial criativo das pessoas no ambiente organizacional. Revista da Católica, São Paulo, v.3, n.5, jan. jul. 2011.

- STEFANO, S. Liderança e suas relações com a estratégia de pessoas e o bem-estar organizacional: um estudo comparativo em duas instituições financeiras internacionais. Tese de Doutorado. São Paulo, 2008.

- STONER, James A. F. e FREEMAN, R. Edward. Administração. Rio de. Janeiro: Livros Técnicos e Científicos, 1999.

- VIEIRA, Anderson Alex de Assis. O Impacto do Desenvolvimento de Liderança no Clima Organizacional.2011.48f.Monografia (Graduação em Administração). Faculdade de Economia, Administração e Contabilidade, Universidade de São Paulo, São Paulo,2011. Disponível em: http://www.progep.org.br/MelhoresEmpresas/InfoDocs/O\%20Impacto\%20do \%20Desenvolvimento\%20de\%20Lideran\%C3\%A7as\%20no\%20Clima\%20Organiz acional.pdf. Acesso em: 21 de mai.2014. 